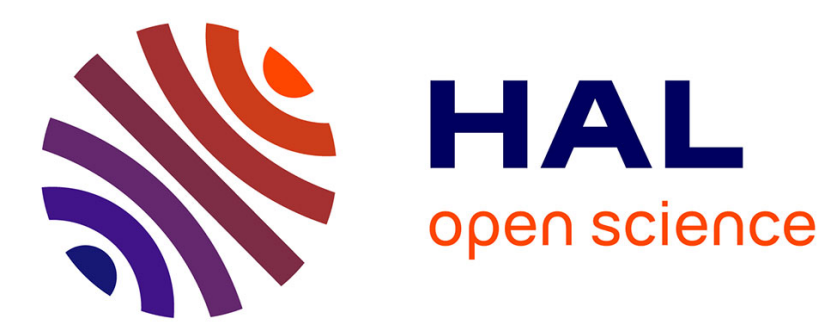

\title{
Type IV Collagen as a Tumour Marker for Colorectal Liver Metastases
}

H. Nyström, P. Naredi, L. Hafström, M. Sund

\section{To cite this version:}

H. Nyström, P. Naredi, L. Hafström, M. Sund. Type IV Collagen as a Tumour Marker for Colorectal Liver Metastases. EJSO - European Journal of Surgical Oncology, 2011, 10.1016/j.ejso.2011.04.010 . hal-00710919

\section{HAL Id: hal-00710919 https://hal.science/hal-00710919}

Submitted on 22 Jun 2012

HAL is a multi-disciplinary open access archive for the deposit and dissemination of scientific research documents, whether they are published or not. The documents may come from teaching and research institutions in France or abroad, or from public or private research centers.
L'archive ouverte pluridisciplinaire HAL, est destinée au dépôt et à la diffusion de documents scientifiques de niveau recherche, publiés ou non, émanant des établissements d'enseignement et de recherche français ou étrangers, des laboratoires publics ou privés. 


\section{Accepted Manuscript}

Title: Type IV Collagen as a Tumour Marker for Colorectal Liver Metastases

Authors: H. Nyström, P. Naredi, L. Hafström, M. Sund

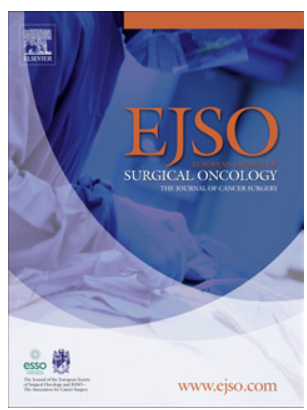

PII: S0748-7983(11)00280-0

DOI: $\quad$ 10.1016/j.ejso.2011.04.010

Reference: $\quad$ YEJSO 3155

To appear in: European Journal of Surgical Oncology

Accepted Date: 25 April 2011

Please cite this article as: Nyström H, Naredi P, Hafström L, Sund M. Type IV Collagen as a Tumour Marker for Colorectal Liver Metastases, European Journal of Surgical Oncology (2011), doi: 10.1016/ j.ejso.2011.04.010

This is a PDF file of an unedited manuscript that has been accepted for publication. As a service to our customers we are providing this early version of the manuscript. The manuscript will undergo copyediting, typesetting, and review of the resulting proof before it is published in its final form. Please note that during the production process errors may be discovered which could affect the content, and all legal disclaimers that apply to the journal pertain. 


\title{
Type IV collagen as a tumour marker for colorectal liver
}

\section{metastases}

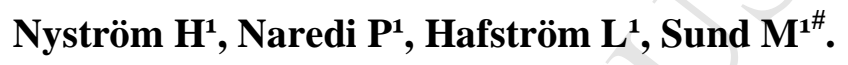 \\ ${ }^{1}$ Department of Surgical and Perioperative Sciences/ Surgery, Umeå University, \\ Umeå SE-901 85, Sweden
}

$\begin{array}{ll}\text { \#Corresponding author: } & \text { Malin Sund, M.D., Ph.D. } \\ & \text { Department of Surgery } \\ & \text { Umeå University Hospital } \\ & \text { SE.90185 Umeå } \\ & \text { SWEDEN } \\ & \text { Tel: +46-90-7850000 } \\ & \text { Fax: +46-90-7851156 } \\ & \text { E-mail: malin.sund@ @urgery.umu.se }\end{array}$ 


\section{ABSTRACT}

Background: About 50\% of patients with primary colorectal cancer (CRC) will develop liver metastases (CLM). Currently, carcinoembryonic antigen (CEA) is the most common tumour marker for CRC and CLM. However, the sensitivity and specificity of this marker is not optimal, as almost $50 \%$ of patients have tumours that do not produce CEA. Therefore there is a need for better markers for CRC and CLM.

Methods: The circulating levels of type IV collagen were measured in patients with CLM, primary CRC and in healthy controls. The expression pattern of type IV collagen was studied by immunofluorescence in CLM and normal liver tissue. The metastatic volume of CLM in the liver was estimated from CT.

Results: In CLM tissue type IV collagen is highly expressed in the areas of desmoplasia. Patients with primary CRC (Dukes' A-C) did not show any increase in circulating type IV collagen compared to healthy controls. However, patients with CLM have significantly elevated levels of circulating type IV collagen when compared to patients with primary CRC and healthy controls. The levels of type IV collagen decreased during chemotherapy and increased at the time of disease progression. The circulating levels of type IV collagen seem to reflect the tumour burden in the liver.

Conclusions: Type IV collagen has the potential to be used as tumour associated biomarker for CLM. These results indicate the importance of interaction between cancer cells and the stroma in the tumour microenvironment.

Keywords: Collagen/ Basement membrane/ Stroma/ Biomarker/ Cancer 


\section{INTRODUCTION}

Colorectal cancer (CRC) is the third most common cancer in the world, with an estimated 1 million patients diagnosed yearly ${ }^{1}$. About half of these patients already suffer from or will develop colorectal liver metastases (CLM) from their primary tumour. Today the only chance of lasting cure for patients with CLM is to perform radical surgical excision of the metastases. The 5-year survival for liver-resected patients varies between $35-50 \%{ }^{2}$ and is mainly dependent on patient selection. Chemotherapy can slow tumour progression and prolong life expectancy with a few months. Untreated the survival is only 6-9 months 3

Carcinoembryonic antigen (CEA) is a biomarker used for the diagnosis and follow-up of patients with CRC as well as CLM. However, CEA is not specific for CRC and is elevated in several other conditions such as benign liver disease, inflammatory bowel disease, pancreatitis, other cancers and in smokers ${ }^{4,5}$. Moertel et al. reported that CEA had a sensitivity of $59 \%$ in CRC recurrence ${ }^{6}$. A meta-analysis presented by Tan $e t$ al. reported that the sensitivity for detecting CRC recurrence using CEA was $64 \%{ }^{7}$. Other biomarkers that have been studied as potential tumour markers are arginase ${ }^{8}$, CA 19-9, CA 242, CA72-4 and TPS ${ }^{9-12}$. However, the sensitivity and the specificity of these biological markers have not been optimal and their clinical usefulness is limited. Despite the fact that the sensitivity and specificity is not optimal, CEA is the most commonly used tumour marker for CRC and CLM, and is today mainly used as a surveillance tool after surgery for CRC to detect recurrence ${ }^{13}$. As indicated by previous studies there is a need for better, more sensitive tumour markers for CLM. 
A CLM is usually accompanied by areas of desmoplasia, and it is known that a pronounced desmoplastic reaction in primary CRC is an independent marker for poor prognosis ${ }^{14}$. However, less is known about the importance of desmoplasia in CLM. The desmoplastic areas contain multiple extracellular matrix (ECM) components, such as fibrillar collagens (e.g. type I collagen), but also non-fibrillar collagens (e.g. type IV collagen) ${ }^{15}$. The desmoplastic areas together with the non-malignant cells of a cancer are termed the tumour stroma. In the past decade it has become increasingly clear that the stroma is important in tumour progression and can influence the behaviour of cancer cells 16. Therefore, the interaction of cancer cells with the surrounding stroma has become an important aspect of cancer biology, as well as a potential new target of therapy and source of biomarkers ${ }^{17}$.

Type IV collagen is the most abundant protein in basement membranes (BM) of all tissues of the human body. A type IV collagen molecule consists of different combinations of six $\alpha$-chains ( $\alpha$ (IV)- $\alpha 6(\mathrm{IV})$ ), which form triple helical molecules termed protomeres. In the BMs these type IV collagen protomeres form a sheet-like structure, which gives structural stability to the $\mathrm{BM}^{18}$. Different combinations of $\alpha(\mathrm{IV})$ chains gives rise to specialized functions of the BMs in various tissues. Besides its role as a structural protein in all BMs, type IV collagen also influences cell adhesion, migration and differentiation of epithelial cells ${ }^{19}$. It has also been shown that fragments of type IV collagen, named arresten, tumstatin, canstatin and hexastatin, can act as endogenous inhibitors of angiogenesis ${ }^{20-22}$.

An earlier study has shown that circulating type IV collagen levels are elevated in patients with CLM, but not in primary CRC alone and that the levels of type IV collagen 
were related to the hepatic metastatic volume ${ }^{23}$. Here the expression pattern of different $\alpha(I V)$-chains in normal liver, and CLM tissues is studied. We have also measured the circulating levels of type IV collagen before and during chemotherapy, and compared this to the corresponding CEA levels.

\section{MATERIALS AND METHODS}

\section{PATIENTS AND SAMPLE COLLECTION}

Patients with CRC ( $n=32)$ and patients with CLM ( $n=15)$ were included in this study. Samples from control patients were obtained $(n=8)$ from patients undergoing elective surgery for benign diseases. Patient characteristics are shown in Table 1. Plasma samples from patients with CRC were collected prior to colorectal surgery and only included patients with Dukes`A-C. The staging of these patients were done by ultrasound, CT (Computed Tomography), MRI (Magnetic Resonance Imaging) and intraoperative palpation. 2 patients from this CRC group were excluded because of spread disease discovered during surgery of the primary tumour. Plasma samples from patients with CRC LM were collected before chemotherapy ("Pre"), during chemotherapy (2-4 months into treatment) ("Post") and at the time when disease progression was diagnosed ("Progress"). These 15 patients were not eligible for liver resection and were treated within a study by regional intraportal or intraarterial 5-Fluorouracil and intravenous Leucovorin ${ }^{24}$. Only patients with multiple samples available during treatment were included. Two of the 15 patients were missing the progress-sample and for one patient both the post- and the progress-samples were missing. Metastatic volume in the liver was 
estimated based on findings on CT-scans. Patients were divided based on metastatic burden in three groups; $<25 \%, 25-50 \%$ and $>50 \%$ of the liver parenchyma affected. The time point of progression was set by two independent clinicians. Criterias for progression of the disease were radiological finding of tumour progression, findings of extrahepatic spread of the disease/ distant metastasis and clinical findings supporting tumour progression. All samples were frozen and stored in $-80^{\circ} \mathrm{C}$. Normal liver tissue and CLM tissue were obtained during surgery of patients with resectable CLM $(n=10)$. Harvested tissues of CLM included the tumour periphery with the contiguous normal liver parenchyma. The tissue samples were snap frozen in liquid nitrogen and stored at $-80^{\circ} \mathrm{C}$ until analysis. This study was approved by the ethical committee of Umeå University. Informed consent was obtained from all patients.

\section{ELISA ASSAY}

Circulating levels of type IV collagen were measured using the serum Collagen IV EIA kit (Argutus Medical, Dublin, Ireland). The samples were analysed in duplicates according to the manufacturers' protocol. This kit is based on a sandwich-ELISA using two monoclonal antibodies (clones 4H12 and ID3) directed against the 7S and collagenous domain of type IV collagen ${ }^{25}$.

\section{CEA ANALYSIS}

Serum levels of CEA were analysed consecutively at an accredited laboratory. During 1998 - 2002 CEA was analysed by the AxSYM CEA method (Abbott) and during 2002- 
2004 by the Immulite 2000 method (Siemens, formerly DPC). The methods agreed well at transition from AxSYM to Immulite 2000.

\section{IMMUNOHISTOCHEMISTRY}

Hematoxylin and eosin (H\&E) staining was performed according standard protocols on frozen sections. Immunohistochemical staining was performed on $5 \mu \mathrm{m}$ frozen sections using methods earlier described ${ }^{26}$ with the primary antibodies and dilutions as follows; mouse-anti- $\alpha 1(\mathrm{IV}) \mathrm{NC1}$ (Wieslab, Malmo, Sweden, MAB1 1:75) ${ }^{27}$, mouse-anti$\alpha 2$ (IV)7S (Chemicon, Billerica, MA, USA, MAB 1910, 1:400), mouse-anti- $\alpha 3$ (IV) NCl (Wieslab, MAB3 1:75) ${ }^{27}$, mouse-anti- $\alpha 5(\mathrm{IV}) \mathrm{NCl}$ (Wieslab, MAB5 1:75) ${ }^{28}$ and sheepanti-CD31 (R\&D systems, Abingdon, UK). Secondary antibodies used were; donkeyanti-mouse TRITC (Jackson ImmunoResearch lab Inc., Newmarket, UK, 1:100) and donkey-anti-sheep FITC (Jackson ImmunoResearch lab Inc., 1:100). The tissue sections were mounted with a medium containing DAPI (Vectashield, Vector laboratories Inc.). Negative control staining was performed on the tissue with secondary antibodies only.

\section{STATISTICS}

For the statistical analysis comparing groups with different individuals we used the Kruskal-Wallis test. To compare related samples within a group we used the Wilcoxon signed rank test. Values in text and figures are presents as mean \pm SD. SPSS version 17 was used for statistical analysis. 


\section{RESULTS}

\section{Strong expression of type IV collagen in CLM}

In normal liver the $\alpha 1$ - and $\alpha 2$-chain of type IV collagen is expressed in vascular basement membranes (VBM) and in the space of Disse/ perisinusoidal spaces (Figure 1). In the CLM disorganized tissue architecture was seen, together with an intense expression of the $\alpha 1-$ and $\alpha 2-$ chains of type IV collagen in the tumour stroma, especially in areas with abundant desmoplasia (Figure 1). Only weak expression of the $\alpha 3$ - and $\alpha 5$ - chains of type IV collagen were observed in both normal liver tissue as well as in CLM (data not shown).

\section{Increased levels of circulating type IV collagen in patients with CLM}

Circulating levels of type IV collagen were measured using ELISA analysis in controls, CRC patients and in patients with CLM before and during chemotherapy. The levels prior to chemotherapy were significantly higher $(\mathrm{n}=15,384 \pm 244 \mathrm{ng} / \mathrm{mL}, \mathrm{p}<0.001)$ than the levels of the control patients $(106 \pm 35 \mathrm{ng} / \mathrm{mL})$ and patients with CRC (Dukes A-C) $(118 \pm 37 \mathrm{ng} / \mathrm{mL})($ Figure $2 \mathrm{~A})$. The circulating levels of type IV collagen decreased during chemotherapy $(\mathrm{n}=14,296 \pm 169 \mathrm{ng} / \mathrm{mL})$, although not significantly. At the time of verified progress, the type IV collagen levels increased $(n=12,498 \pm 241 \mathrm{ng} / \mathrm{mL}, \mathrm{p}<0.01$ and 0.01 respectively)(Figure 2A) when compared to the "Pre" and "Post" sample. No statistically significant difference of circulating type IV collagen levels could be observed between the different stages of patients with primary CRC (Dukes' A-C)(Figure 2 B). There was also no statistically significant difference between the levels of type IV collagen found in healthy controls when compared to patients with primary CRC (Dukes' A-C). A 
summary over the circulating type IV collagen levels and the statistical analysis when comparing the various groups is shown in Table 2.

Two patients were excluded from the primary CRC group. One patient had a previously unknown CLM at the time when the sample was collected. The second patient had a large primary tumour of CRC growing into the small intestine. These findings were discovered during the surgery of the CRC. Both patients were therefore re-classified as Dukes D. It is of interest that these patients displayed high levels of circulating type IV collagen $(557 \mathrm{ng} / \mathrm{mL}$ and $435 \mathrm{ng} / \mathrm{mL}$, respectively).

\section{Correlation of metastatic volume in the liver and circulating type IV collagen levels}

Patients with a CLM burden of $<25 \%$ of the liver parenchyma displayed a lower level of type IV collagen $(\mathrm{n}=2,137 \pm 3 \mathrm{ng} / \mathrm{mL})$. The patients with a CLM burden of $25-50 \%$ had intermediate levels of type IV collagen $(\mathrm{n}=10,316 \pm 175 \mathrm{ng} / \mathrm{ml})$, and the patients with a CLM burden of $>50 \%$ displayed the highest levels of type IV collagen $(n=3,753 \pm 104$ $\mathrm{ng} / \mathrm{ml}$ ). The groups were all significantly different from one another, when using the Kruskal-Wallis test $(p<0,01)$. There seems to be a correlation between the metastatic burden in the liver of CLM and the circulating levels of type IV collagen. However, this should be verified in a larger patient cohort. The levels of type IV collagen for all individuals are presented in Figure 3. The mean time to disease progression was 10.2 months for patients with a CLM burden of $<25 \%$ of the liver parenchyma, 9.9 months for patients with a CLM burden of 25-50\% and 7.8 months for patients with a CLM burden of $>50 \%$. 


\section{Comparison of circulating levels of type IV collagen and CEA in patients with CLM}

For comparison between CEA and type IV collagen only patients with complete series of pre-, post- and progress- samples were included $(n=12) .10$ out of 11 patients with CEA values available at the time of diagnosis of the CLM had an increased CEA (with 4.8 $\mathrm{ng} / \mathrm{ml}$ used as a cut-off value). 3 values were missing, 1 "pre" and 2 "post". An increase in CEA concentration between the "post" and the "progress" sample by 50\% was considered to indicate progressive disease. Six of 10 patients $(60 \%)$ had a $50 \%$ rise of the CEA value. All 12 patients with CLM had elevated values of type IV collagen before treatment and their values decreased during treatment (Figure 4). An increase in type IV collagen concentration between the "post" and the "progress" sample by 50\% was similarly to CEA considered to indicate disease progression. 9 out of 12 patients $(75 \%)$ had a rise of $50 \%$ of the type IV collagen level. Unfortunately, our material is too small to allow for statistical comparison of CEA and type IV collagen in detecting CLM.

\section{DISCUSSION}

Type IV collagen is normally expressed in the vascular basement membranes and in the space of Disse/ perisinusoidal space in the normal liver ${ }^{29}$. In normal liver tissue type IV collagen is mainly produced by the hepatic stellate cells. The stellate cells are principally located in the space of Disse, and can under pathologic conditions transdiffrentiate into hepatic myofibroblasts, which produce many ECM components such as collagens (type I, III, IV, V and VI), non-collagenous glycoproteins (laminin, fibronectin, elastin) and proteoglycans as well as matrix-degrading enzymes. This increase in ECM production is of special importance in fibrotic liver disease. 
We have shown that type IV collagen expression is highly up-regulated in the desmoplastic areas of the CLM. In the desmoplastic area, the type IV collagen network mainly consists of the $\alpha 1 \alpha 1 \alpha 2$ protomer, with only low expression of the $\alpha 3$ - and $\alpha 5$ chains. The type IV collagen in CLM is highly expressed in the areas of dense desmoplasia surrounding the tumour cells in the stroma, but not as much in the vicinity of the cancer cells themselves. This differs from the expression pattern observed in pancreas cancer, where basically no type IV collagen is found in the dense desmoplastic area, but there is a strong expression in the stroma close to the pancreatic cancer cells ${ }^{30}$.

Interestingly, the levels of circulating type IV collagen in patients with primary CRC (Dukes' A-C) were close to normal and comparable to levels found in control patients. Ambiru et al reported similar findings in CRC where circulating type IV collagen was close to normal ${ }^{23}$. Additionally, the Dukes'stage did not correlate with any rise in type IV collagen levels. The Dukes' Staging System is used to stage CRC and consists of four different stages (A-D). While Dukes' A and B tumours are limited to the colon or rectal wall, Dukes' C tumours have spread to the local lymph nodes. In Dukes' D tumours distant metastases or a local spread to adjacent organs is found. Two patients were excluded from our primary CRC group because of unknown disseminated tumour disease. Interestingly, both these patients had high levels of circulating type IV collagen. Although our control patients where somewhat younger than the patients with CLM, it has previously been shown that no significant differences in circulating type IV collagen can be seen when comparing individuals in these age groups ${ }^{31}$. Our findings support that the circulating levels of type IV collagen seem to reflect the tumour burden in the liver of CLM. 
CEA is today the most established tumour marker used for CRC and CLM, with its clinical applications mainly in diagnosis and follow-up. As earlier mentioned, CEA is not optimal in sensitivity and specificity, but nevertheless the best tumour marker known for CRC currently. The patients in this study were not candidates for surgical resection due to the extent of the metastases. The majority of these patients presented with a high pre-sample of CEA. This differs from the percentage of CLM patients in general, where only approximately 50-60\% of the patients have a high CEA at the time of diagnosis. It is well known that a high preoperative level of CEA, both in the case of CRC, and in the presence of CLM is a poor prognostic factor, and that this marker has its main value in monitoring recurrence after surgery of primary CRC. ${ }^{32} 13$.

The desmoplastic reaction is associated with a poor prognosis in $\mathrm{CRC}^{14}$ as well as for other epithelial cancers. It has been proposed that the cancer cells in CRC can provoke an inflammatory response in the liver, which then initiates the hepatic wound healing response. In this response, hepatic stellate cells transdiffrentiate into myofibroblasts producing the ECM components seen in the areas of desmoplasia. Potentially this leads to selection of CRC clones that can survive in the presence of the desmoplasia, and which may actually benefit from interactions with the ECM components. This is in contrast to what was initially believed, when the desmoplastic reaction in CLM rather was considered a mechanism for the organism to protect and encapsulate itself from the cancer cells ${ }^{33}$.

We have shown that the $\alpha 1$ and $\alpha 2$ chains of type IV collagen are major components seen in the desmoplastic reaction of CLM. We have also shown that the circulating levels of type IV collagen are strongly elevated in the presence of CLM. 
Interestingly, the levels of circulating type IV collagen also seem to reflect the tumour load in the liver. Our findings show that type IV collagen has the potential to be used as a tumour marker in patients with CRC to detect CLM. This is of importance, since the main reason for mortality in cancer patients is caused by the metastatic spread of the disease. Many patients with CLM can be treated with surgical resection with a curative intention and/or have treatment with chemotherapy and targeted drugs. An optimal tumour marker to detect CLM and to follow treatment efficacy is therefore of great importance. Studies should be made in this area with larger groups of patients. This study indicates that type IV collagen can be used as a tumour marker in the follow-up of patients with CRC to detect CLM.

\section{FIGURE LEGENDS}

Figure 1. Expression of type IV collagen in normal liver (A, C, E) and in CLM (B, D, F). (A , B) Light microscopy images stained with H\&E visualizes the difference between normal liver tissue and CLM. (C, E) In normal liver the $\alpha 1(\mathrm{IV})-$ and $\alpha 2(\mathrm{IV})-$ chains are expressed in the Space of Disse and in vascular BMs (red). (D, F) In CLM tissue the $\alpha 1(\mathrm{IV})-$ and $\alpha 2(\mathrm{IV})-$ chains are strongly expressed (red) in the desmoplastic reaction (DR) as well as in VBMs. The normal architecture of the liver is replaced by tumour cells and stroma, rich in type IV collagen. Blood vessels are visualized by the endothelial marker CD 31 (green) and cell nuclei by DAPI (blue).

Figure 2. (A) Levels of circulating type IV collagen in controls, in patients with CRC (Dukes' A-C) and CLM. The sample "pre" illustrate levels prior to chemotherapy in the 
CLM group. Type IV collagen is significantly higher in all groups representing the patients with CLM when compared to healthy controls and patients with CRC $(\mathrm{p}<0.001)$. The sample "post" is taken after 2-4 months of chemotherapy in the CLM group and shows decreased levels of type IV collagen. The sample "progress" shows increased levels of type IV collagen in the CLM group at the time of progression, and is significantly higher than the pre-sample and the post-sample $(\mathrm{p}<0.01$ and $\mathrm{p}<0.01$, respectively). (B) Levels of circulating type IV collagen in patients with CRC, Dukes stage A, B and C. No significant difference in type IV collagen was found between the different stages.

Figure 3. Levels of circulating type IV collagen correlated to the metastatic burden of CLM in the liver. Patients with CLM burden $<25 \%$ of liver parenchyma (1) display the lowest levels of type IV collagen, patients with CLM burden 25-50\% (2) display intermediate levels, and patients with CLM burden $>50 \%$ (3) shows the highest levels of type IV collagen.

Figure 4. Comparison between the levels of circulating CEA and type IV collagen in patients with CLM. (A) All 12 patients had significantly increased levels of type IV collagen prior to chemotherapy. The levels for all patients decreased during chemotherapy. 9 of 12 patients $(75 \%)$ did show a $50 \%$ rise of type IV collagen from the "post" to the "progress" sample. (B) 10 out of 11 patients had a high CEA at the time of diagnosis. Most of these patients showed a decreased level of CEA during treatment. 6 of 
10 patients $(60 \%)$ did show a $50 \%$ rise of the CEA from the "post" to the "progress" sample.

\section{ACKNOWLEDGEMENTS}

We thank Anette Berglund and Christina Lundin for skillful technical assistance and Associate professor Hans Stenlund for statistical supervision.

\section{FUNDING}

This study was supported by grants from Cancerforskningsfonden i Norrland, the Young Investigator Award of Umeå University, Insamlingsstiftelsen för Medicinsk Forskning vid Umeå universitet, Svenska Sällskapet för Medicinsk Forskning, Västerbotten County Council and JC Kempe Memorial Foundation Scholarship Fund. The funding agents did not influence the article in any way.

\section{CONFLICT OF INTEREST STATEMENT}

The authors have no conflict of interest.

\section{REFERENCES}

1. Parkin DM, Bray F, Ferlay J, Pisani P. Global cancer statistics, 2002. CA Cancer J Clin 2005;55(2):74-108.

2. Mayo SC, Pawlik TM. Current management of colorectal hepatic metastasis. Expert Rev Gastroenterol Hepatol 2009;3(2):131-44. 
3. Cromheecke M, de Jong KP, Hoekstra HJ. Current treatment for colorectal cancer metastatic to the liver. Eur J Surg Oncol 1999;25(5):451-63.

4. George PK, Loewenstein MS, O'Brien MJ, et al. Circulating CEA levels in patients with fulminant hepatitis. Dig Dis Sci 1982;27(2):139-42.

5. van der Schouw YT, Verbeek AL, Wobbes T, Segers MF, Thomas CM. Comparison of four serum tumour markers in the diagnosis of colorectal carcinoma. $\mathrm{Br} J$ Cancer 1992;66(1):148-54.

6. Moertel CG, Fleming TR, Macdonald JS, et al. An evaluation of the carcinoembryonic antigen (CEA) test for monitoring patients with resected colon cancer. JAMA 1993;270(8):943-7.

7. Tan E, Gouvas N, Nicholls RJ, et al. Diagnostic precision of carcinoembryonic antigen in the detection of recurrence of colorectal cancer. Surg Oncol 2009;18(1):15-24.

8. Mielczarek M, Chrzanowska A, Scibior D, et al. Arginase as a useful factor for the diagnosis of colorectal cancer liver metastases. Int J Biol Markers 2006;21(1):40-4.

9. Carpelan-Holmstrom M, Louhimo J, Stenman UH, et al. CEA, CA 242, CA 19-9, CA 72-4 and hCGbeta in the diagnosis of recurrent colorectal cancer. Tumour Biol 2004;25(5-6):228-34.

10. Griesenberg D, Nurnberg R, Bahlo M, Klapdor R. CEA, TPS, CA 19-9 and CA 72-4 and the fecal occult blood test in the preoperative diagnosis and follow-up after resective surgery of colorectal cancer. Anticancer Res 1999;19(4A):2443-50.

11. Holubec L, Jr., Topolcan O, Pikner R, et al. The significance of CEA, CA19-9 and CA72-4 in the detection of colorectal carcinoma recurrence. Anticancer Res 2000;20(6D):5237-44. 
12. Nicolini A, Caciagli M, Zampieri F, et al. Usefulness of CEA, TPA, GICA, CA 72.4, and CA 195 in the Diagnosis of primary colorectal cancer and at its relapse. Cancer Detect Prev 1995;19(2):183-95.

13. Duffy MJ, van Dalen A, Haglund C, et al. Tumour markers in colorectal cancer: European Group on Tumour Markers (EGTM) guidelines for clinical use. Eur J Cancer 2007;43(9):1348-60.

14. Sis B, Sarioglu S, Sokmen S, et al. Desmoplasia measured by computer assisted image analysis: an independent prognostic marker in colorectal carcinoma. J Clin Pathol 2005;58(1):32-8.

15. Conti JA, Kendall TJ, Bateman A, et al. The desmoplastic reaction surrounding hepatic colorectal adenocarcinoma metastases aids tumor growth and survival via alphav integrin ligation. Clin Cancer Res 2008;14(20):6405-13.

16. Radisky D, Muschler J, Bissell MJ. Order and disorder: the role of extracellular matrix in epithelial cancer. Cancer Invest 2002;20(1):139-53.

17. Sund M, Kalluri R. Tumor stroma derived biomarkers in cancer. Cancer Metastasis Rev 2009;28(1-2):177-83.

18. Hudson BG, Tryggvason K, Sundaramoorthy M, Neilson EG. Alport's syndrome, Goodpasture's syndrome, and type IV collagen. N Engl J Med 2003;348(25):2543-56.

19. Khoshnoodi J, Pedchenko V, Hudson BG. Mammalian collagen IV. Microsc Res Tech 2008;71(5):357-70.

20. Kamphaus GD, Colorado PC, Panka DJ, et al. Canstatin, a novel matrix-derived inhibitor of angiogenesis and tumor growth. J Biol Chem 2000;275(2):1209-15. 
21. Kalluri R. Basement membranes: structure, assembly and role in tumour angiogenesis. Nat Rev Cancer 2003;3(6):422-33.

22. Sund M, Hamano Y, Sugimoto H, et al. Function of endogenous inhibitors of angiogenesis as endothelium-specific tumor suppressors. Proc Natl Acad Sci U S A 2005;102(8):2934-9.

23. Ambiru S, Miyazaki M, Nakagawa K, Nakajima N. Increased serum type IV collagen 7-S levels in patients with hepatic metastasis. Am J Gastroenterol 1995;90(5):783-7.

24. Naredi P, Oman M, Blind PJ, et al. A comparison between hepatic artery ligation and portal 5-Fu infusion versus 5-Fu intra arterial infusion for colorectal liver metastases. Eur J Surg Oncol 2003;29(5):459-66.

25. Obata $\mathrm{K}$, Iwata $\mathrm{K}$, Ichida $\mathrm{T}$, et al. One step sandwich enzyme immunoassay for human type IV collagen using monoclonal antibodies. Clin Chim Acta 1989;181(3):293303.

26. Hamano Y, Zeisberg M, Sugimoto H, et al. Physiological levels of tumstatin, a fragment of collagen IV alpha3 chain, are generated by MMP-9 proteolysis and suppress angiogenesis via alphaV beta3 integrin. Cancer Cell 2003;3(6):589-601.

27. Johansson C, Butkowski R, Wieslander J. Characterization of monoclonal antibodies to the globular domain of collagen IV. Connect Tissue Res 1991;25(3-4):229-41.

28. Ding J, Kashtan CE, Fan WW, et al. A monoclonal antibody marker for Alport syndrome identifies the Alport antigen as the alpha 5 chain of type IV collagen. Kidney Int 1994;45(5):1504-6.

29. Yoshimura K, Meckel KF, Laird LS, et al. Integrin alpha2 mediates selective metastasis to the liver. Cancer Res 2009;69(18):7320-8. 
30. Ohlund D, Lundin C, Ardnor B, et al. Type IV collagen is a tumour stroma-derived biomarker for pancreas cancer. Br J Cancer 2009;101(1):91-7.

31. Yokoya Y, Iwata K, Muragaki Y, et al. Concentration of serum laminin and type IV collagen in liver diseases assayed by a sandwich enzyme-immunoassay using monoclonal antibodies. Clin Chim Acta 1992;210(1-2):109-18.

32. Park IJ, Choi GS, Lim KH, Kang BM, Jun SH. Serum Carcinoembryonic Antigen Monitoring After Curative Resection for Colorectal Cancer: Clinical Significance of the Preoperative Level. Ann Surg Oncol 2009.

33. Lunevicius R, Nakanishi H, Ito $\mathrm{S}$, et al. Clinicopathological significance of fibrotic capsule formation around liver metastasis from colorectal cancer. J Cancer Res Clin Oncol 2001;127(3):193-9. 
Table 1 Patient Characteristics

\begin{tabular}{lccc}
\hline & Control & Primary CRC & CLM \\
\hline $\begin{array}{l}\text { Sex } \\
\text { (\% females/males) }\end{array}$ & $62 / 38$ & $34 / 66$ & $27 / 73$ \\
Diagnosis & Diverticular disease (2) & CRC (32) & CLM (15) \\
(number of patients) & Gallstone disease (6) & & \\
Age in years & 51 [27-71] & $66[26-80]$ & $63[45-76]$ \\
(mean) [range] & & & $0 / 5 / 9 / 1$ \\
Dukes stage (A/B/C/D) & - & $8 / 14 / 10$ & \\
of primary tumor & - & - & 8.7 [2.2-25.9] \\
Time of treatment ${ }^{1}$ & - & - & \\
(mean) [range] & - & & \\
Chemotherapy & - & & \\
(i.a/ i.p) & & & \\
CEA at diagnosis & & & \\
(ng/ml) & & & \\
\hline
\end{tabular}

${ }^{\text {T }}$ Indicates treatment with chemotherapy in months 
Table 2. Statistical comparison of type IV collagen concentrations between groups

\begin{tabular}{lcccccc}
\hline & $\begin{array}{c}\text { Mean type IV } \\
\text { collagen level } \\
\text { (ng/mL, SD) }\end{array}$ & Control & CRC & "Pre" & "Post" & "Progress" \\
\hline Control & $106 \pm 35$ & - & n.s & $<0.001$ & $<0.001$ & $<0.001$ \\
CRC & $118 \pm 37$ & n.s & - & $<0.001$ & $<0.001$ & $<0.001$ \\
"Pre" & $384 \pm 244$ & $<0.001$ & $<0.001$ & - & n.s & $<0.01$ \\
"Post" & $296 \pm 169$ & $<0.001$ & $<0.001$ & n.s & - & $<0.01$ \\
"Progress" & $498 \pm 241$ & $<0.001$ & $<0.001$ & $<0.01$ & $<0.01$ & - \\
\hline
\end{tabular}

Abbreviations: $n . s=$ not significant 
A

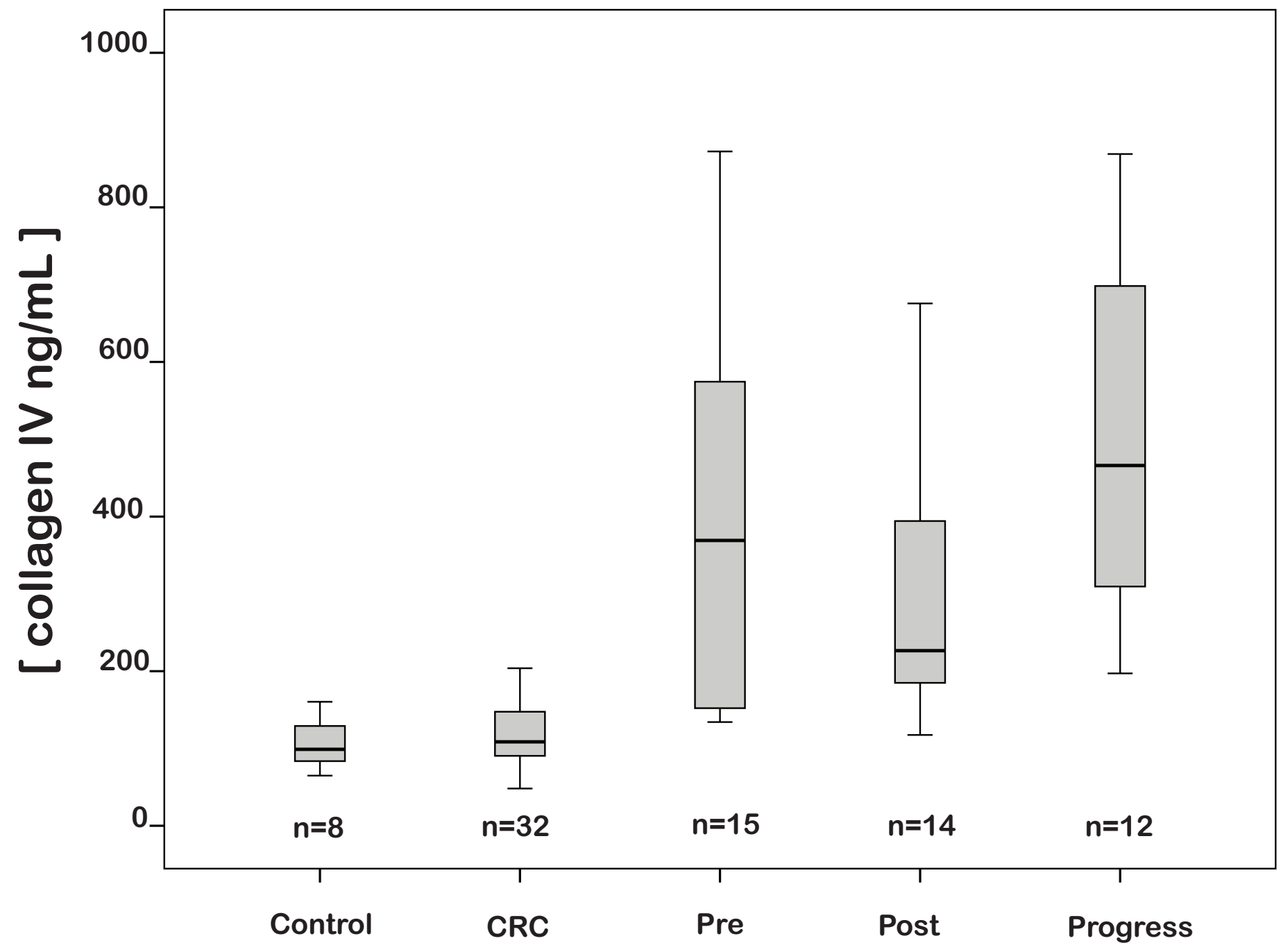

B

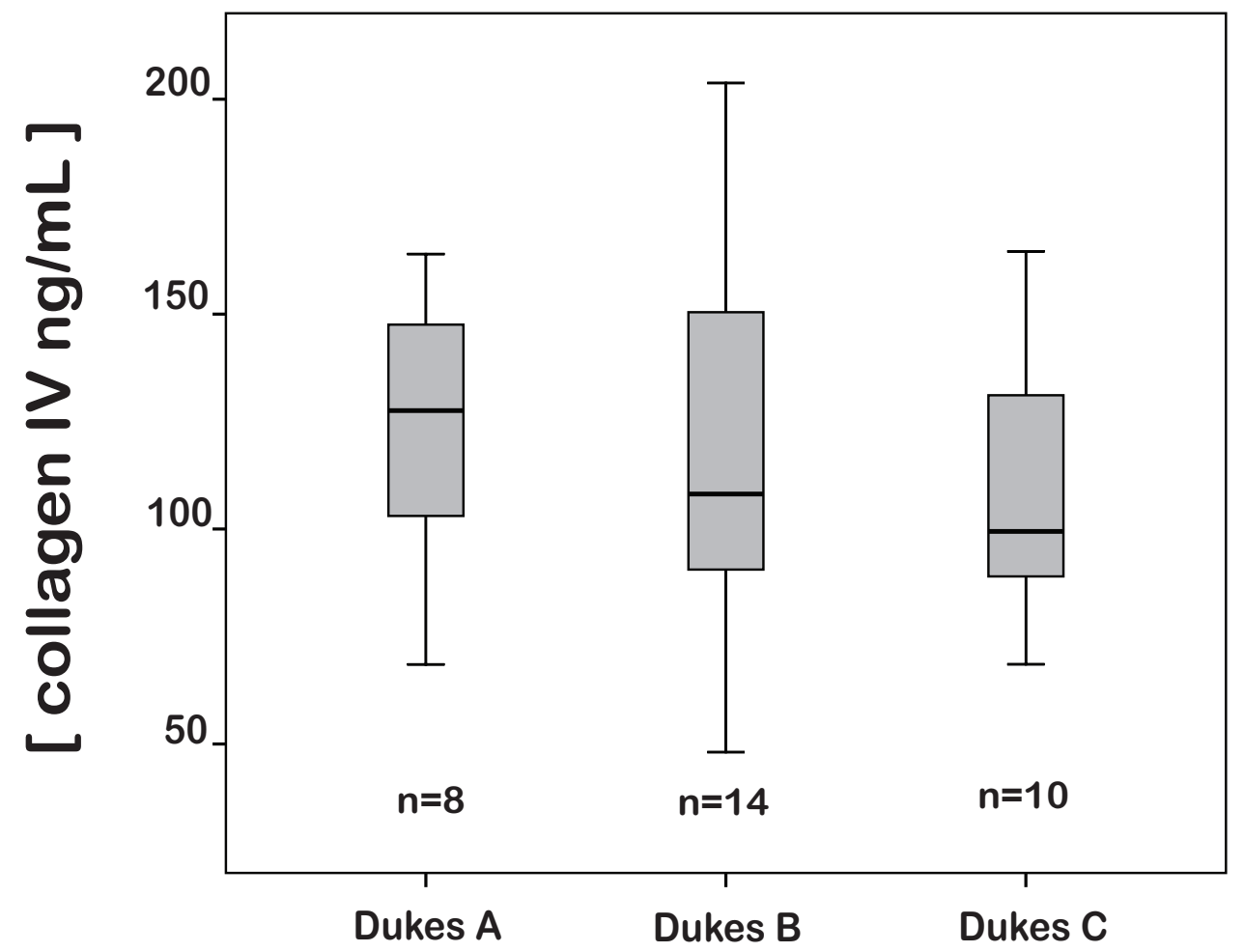



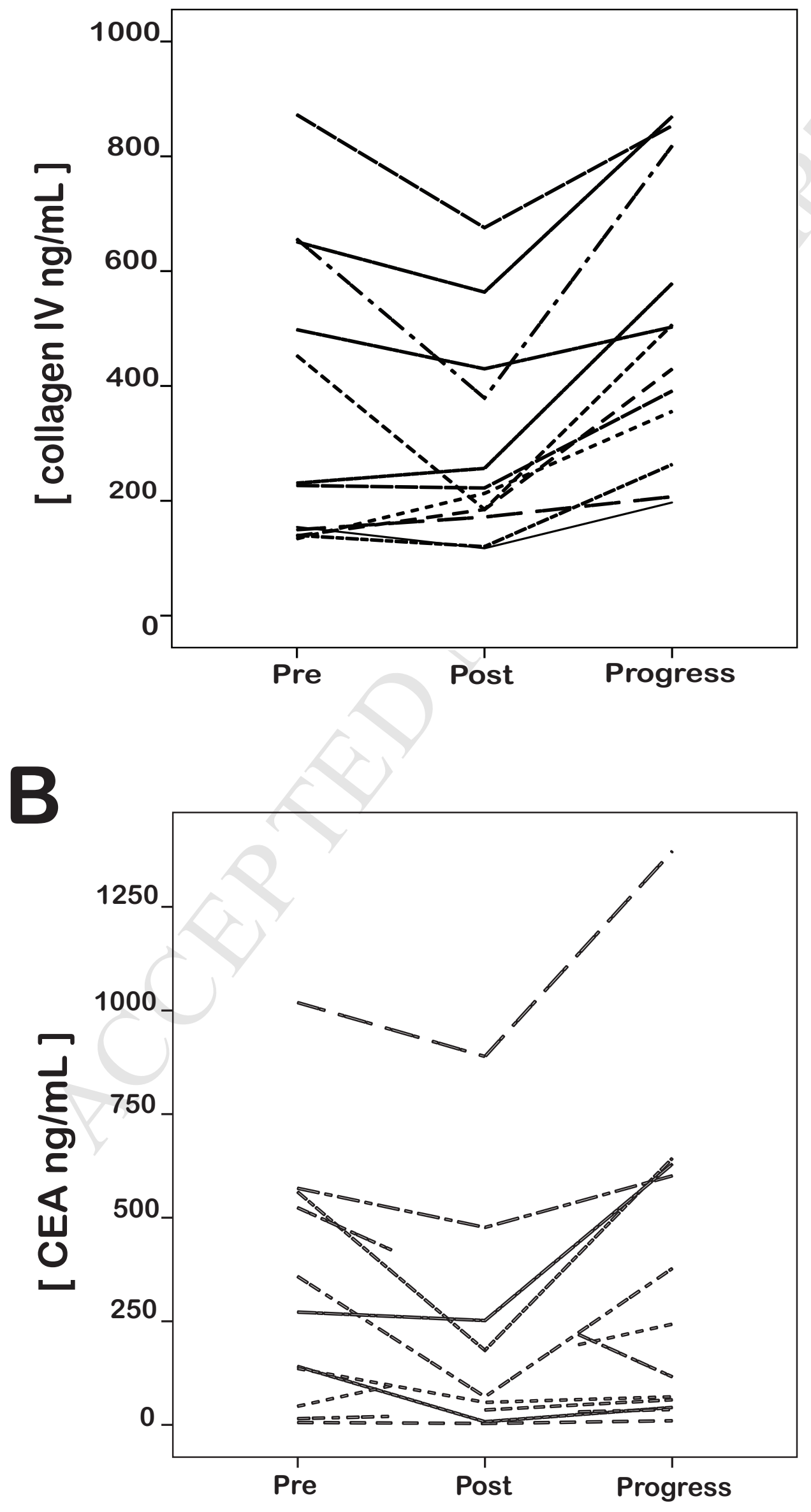